NOTE

\title{
Studies on the Formation of Graft Copolymer by Coupling Reactions III. Temperature Effects on the Formation of Long Branched Polystyrene
}

\author{
Koji IshizU, Shinsuke Hagiwara, Takashi FuKuTOMI, \\ and Toshio KAKURAI \\ Department of Polymer Science, Tokyo Institute of Technology, \\ 12-1, Ookayama 2-chome, Meguro-ku, Tokyo 152, Japan
}

(Received May 12, 1982)

\begin{abstract}
KEY WORDS Long Branched Polystyrene / Coupling Reaction / Polystyryl Anion / Chloromethylated Polystyrene / Gel-Permeation Chromatograph / Grafting Site /
\end{abstract}

In a previous paper, ${ }^{1}$ we dealt with the formation of long branched polystyrene by a coupling reaction between poly(methyl methacrylate) (PMMA) and poly- $\alpha$-methylstyryl anion. We concluded that the structure of the long branched polystyrene was subject to changes depending on the reaction conditions: e.g., the ratio of a good solvent [tetrahydrofuran (THF)] to a poor solvent (methylcyclohexane), even when there was the same degree of polymerization (DP) of PMMA and poly- $\alpha$-methylstyryl anion. Our results show that all the pendant groups on the backbone polymer did not react with an equal probability under various reaction conditions even at the initial stage of the reaction. In another paper, ${ }^{2}$ we investigated the effects of the DP of the backbone and the side chain on the grafting site of the long branched polystyrene using the calibration of star polystyrene. It was found that the polystyryl anion reacted near the ends of the backbone molecule; the amount of anion which reacted increased with increasing DP of polystyryl anion and with decreasing DP of the backbone polymer. Altares et al., ${ }^{3}$ Pannell, ${ }^{4}$ and $\mathrm{we}^{5}$ have reported the reaction of polystyryl anion with chloromethylated polystyrene, and obtained comb-shaped polystyrene with branches attached at random to the backbone.

In this paper, we report the effects of reaction temperature on the grafting site of long branched polystyrene. The chloromethylated polystyrene was reacted with polystryl anion in THF by varying the reaction temperature. The reaction conditions were chosen so as to produce the long branched polystyrene. On the other hand, star polystyrenes consisting of three branches were synthesized in such a way that each had a different DP. The relationship between the elution peak count in gel-permeation chromatograph (GPC) and the DP of each branch was obtained for these star polystyrene. ${ }^{2}$ The grafting site of the long branched polystyrene was inferred from these calibrations.

\section{EXPERIMENTAL}

Polystyryl anion was prepared by polymerization of styrene monomer with cumyl potassium in THF. The concentration of the polystyryl anion was measured by a Hitachi Spectrophotometer Model 124 at $\lambda_{\max }=346 \mathrm{~nm}(\log \varepsilon=4.06) .{ }^{6}$ The polystyrene was chloromethylated with chloromethyl methyl ether using stannic chloride as the catalyst. ${ }^{7}$ In order to determine the chlorine content, the chloromethylated polystyrene was reacted with a large excess of sodium naphthalene in THF, and the $\mathrm{NaCl}$ produced was titrated by Volhard's method. ${ }^{8}$

The coupling reaction was done by varying the reaction temperature, and keeping the concentration of the polystyryl anion ( $\left.\mathrm{DP}=\mathrm{P}_{1}\right)$ very low, compared with the concentration of chloromethylated polystyrene $\left(\mathrm{DP}=\mathrm{P}_{2}+\mathrm{P}_{3}: \mathrm{P}_{2}\right.$ and $\mathrm{P}_{3}$ are $\mathrm{DP}$ of the backbone parts divided at a branched point) so 
as to form the long branched polystyrene (solvent, THF; reaction temperature, $-78-25^{\circ} \mathrm{C}$ ). The GPCs of the products were obtained and improved by a reshaping method. ${ }^{9}$ The GPC measurements were repeated three times. Each GPC profile thus obtained was summed and the averaging operation was carried out to cancel any observational errors. The synthetic method of a star polystyrene and procedure for its calibration are described in a previous report. ${ }^{2}$ The number-average molecular weight $\left(M_{n}\right)$ of linear polystyrene was calculated from the GPC peak using the calibration of standard polystyrene samples. Gel-permeation data were obtained on a Toyo Soda High Speed Liquid

Table I. Conditions for coupling reactions between chloromethylated polystyrene and polystyryl anions (solvent, THF)

\begin{tabular}{|c|c|c|c|}
\hline \multirow{2}{*}{ No. } & $\begin{array}{l}\text { Backbone }^{\mathrm{a}} \\
\text { concn } \times 10^{3}\end{array}$ & $\begin{array}{c}\text { Polystyryl } \\
\text { anion }^{\mathbf{b}}\end{array}$ & Temperature \\
\hline & $\begin{array}{c}\text { molar number of } \\
\text { molecule } 1^{-1}\end{array}$ & $\mathrm{moll}^{-1}$ & ${ }^{\circ} \mathrm{C}$ \\
\hline GR1 & 1.87 & 4.22 & 25 \\
\hline GR2 & 1.64 & 4.22 & -25 \\
\hline GR3 & 1.70 & 4.22 & -78 \\
\hline
\end{tabular}

a Chloromethylated polystyrene; $M_{n}=4.8 \times 10^{4}(\mathrm{DP}=$ 462; chloromethyl groups $=76 / 1$-polymer).

b $\mathrm{DP}=942$.

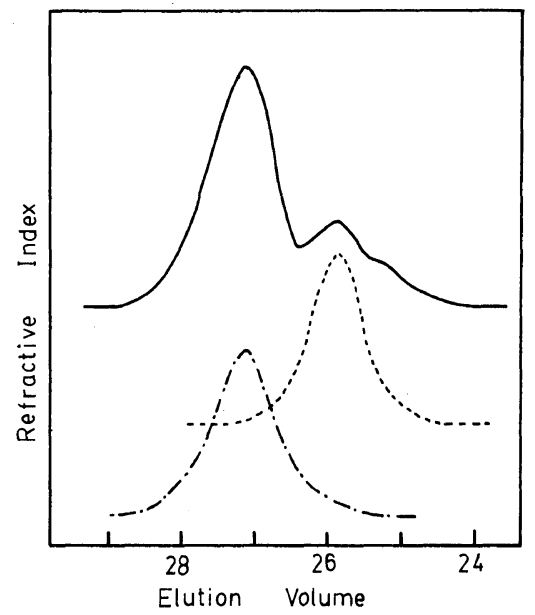

Figure 1. GPC profiles of GR1 series: - , reaction product (GR1); -----, polystyryl anion; ----, chloromethylated polystyrene.
Chromatograph HLC-801A. Measurements were made in distilled THF at $40^{\circ} \mathrm{C}$ with a GMH column at a flow rate of $1.4 \mathrm{ml} \mathrm{min}^{-1}$.

\section{RESULTS AND DISCUSSION}

Table I shows the reaction conditions for the

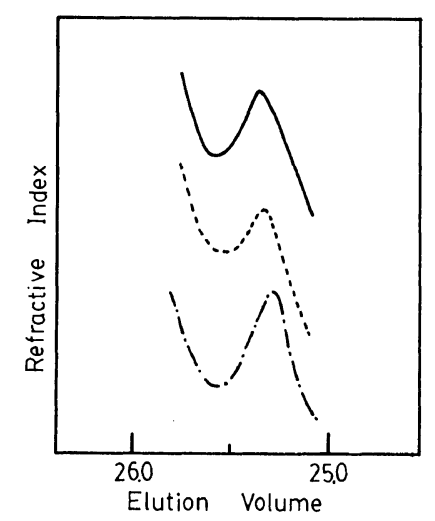

Figure 2. Reshaped GPC profiles of GRG1-GRG3: -, GRG1; --.--, GRG2; -.-_-, GRG3.

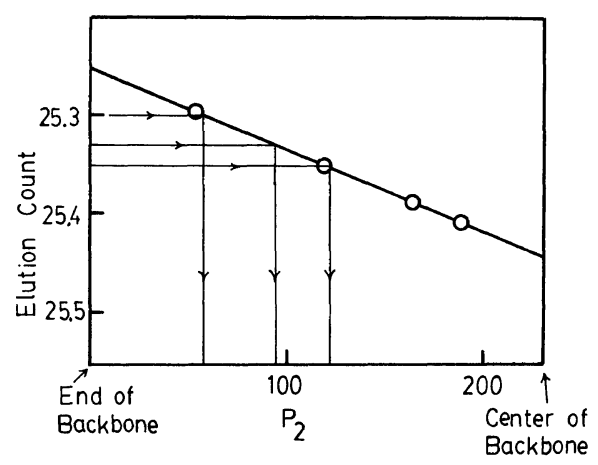

Figure 3. Relationship between elution count and $P_{2}$ for star polystyrene: $O, P_{1}+P_{2}+P_{3}$.

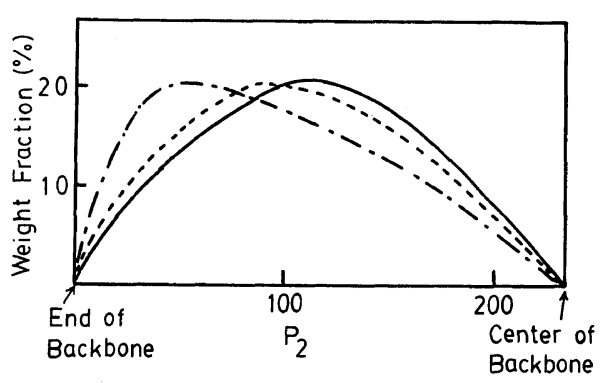

Figure 4. Distributions of grafting sites for GRG1GRG3: ——, GRG1; -----, GRG2; ----, GRG3. 
synthesis of the long branched polystyrene by varying the reaction temperature. Figure 1 shows a typical set of GPC profiles of GR1, polystyryl anion, and chloromethylated polystyrene. The GPC peak at 27.2 and 25.9 counts agree with those of the unreacted chloromethylated polystyrene and homo polystyrene produced as a result of impurities in this reaction system, respectively. After deducting the GPC distribution of the polystyryl anion from that of the reaction products, the GPC of the long branched polystyrene (GRG series) was improved by the reshaping method (Figure 2). The grafting sites of GRG1-GRG3 could be read from the calibration of the star polystyrenes. Figure 3 shows the relationship between $P_{2}$ and the elution peak counts of the star polystyrenes, as $\mathrm{P}_{2}$ and $\mathrm{P}_{3}$ change under the conditions of $P_{1}=942$ and $\left(P_{2}+P_{3}\right)=$ $462^{2}$. The elution peak counts of GRG1 (25.35), GRG2 (25.33), and GRG3 (25.30) can be read from Figure 2. In Figure 3, the grafting sites corresponding to these values are shown by arrows. By using the calibration curve of the star polystyrenes, the elution volumes of the reshaped GPC profiles for GRG1-GRG3 can be transformed into $P_{2}$. Figure 4 shows the distribution of grafting sites in the long branched polystyrene. Thus, the polystyryl anions tend to react near the ends of the backbone molecule as the reaction temperature decreases. The main factor involved in this is considered to be the hydrodynamical dimensions of the polymer molecules. These dimensions expand with increasing temperature. Especially in the case of the GRG3 (reaction temperature, $-78^{\circ} \mathrm{C}$ ), the polystyryl anion reacts with the end pendant group located farthest away from the center of gravity of the backbone molecule.

\section{REFERENCES}

1. K. Ishizu, T. Fukutomi, T. Kakurai, and T. Noguchi, Polym. J., 4, 105 (1973).

2. K. Ishizu, T. Fukutomi, and T. Kakurai, Polym. J., 7, 570 (1975).

3. T. Altares, Jr., D. P. Wyman, and V. R. Allen, J. Polym. Sci., A, 3, 4131 (1965).

4. J. Pannell, Polymer, 12, 558 (1971).

5. K. Ishizu, T. Fukutomi, and T. Kakurai, Polym. J., 7, 228 (1975).

6. R. Asami, M. Levy, and M. Szwarc, J. Chem. Soc., 361 (1962).

7. G. D. Jones, Ind. Eng. Chem., 44, 2686 (1952).

8. G. Iwasaki, "Bunseki Kagaku Gaisetsu (Introduction to Quantitative Analysis)," Gakujutsutosho, Tokyo, 1963, p 276.

9. P. E. Pierce and J. E. Armonas, J. Polym. Sci., C, 21, 23 (1968). 